\title{
The Karonga Prevention Trial: a leprosy and tuberculosis vaccine trial in Northern Malawii. I. Methods of the vaccination phase
}

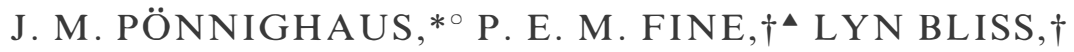 \\ P. J. K. GRUER, ${ }^{*}$, B. KAPIRA-MWAMONDWE, ${ }^{*}$ \\ E. MSOSA, ${ }^{*}$ R. J. W. REES, $\ddagger$ D. CLAYTON,§ \\ M. C. PIKE, J. A. C. STERNE† \& \\ SUSAN M. OXBORROW* \\ *LePra, P.O. Box 46, Chilumba, Malawi; $\dagger$ Communicable Disease \\ Epidemiology Unit, Department of Epidemiology and Population \\ Sciences, London School of Hygiene and Tropical Medicine, Keppel \\ Street, London WCIE 7HT, England; $\$$ National Institute for \\ Medical Research, The Ridgeway, Mill Hill, London NW7, \\ England; §Medical Research Council Biostatistics Unit, Institute of \\ Public Health, University Forvie Site, Robinson Way, Cambridge \\ CB2 2SR; and $\uparrow$ Department of Preventive Medicine, University of \\ Southern California, School of Medicine, Los Angeles, California \\ USA
}

Accepted for publication 27 April 1993

\begin{abstract}
Summary In this report the methods of the Karonga Prevention Trial, a doubleblind leprosy and tuberculosis vaccine trial in Karonga District, Northern Malawi i, are described in detail. During a total population house-to-house survey, which lasted from November 1985 until August 1989, 121,008 people (57,892 males and 63,116 females) were vaccinated. A further 5835 people refused vaccination and 5757 were ineligible for vaccination, 2652 of them because they had a history or signs of leprosy, or because they were suspected to have early leprosy. A total of 66,145 individuals, without evidence of prior BCG vaccination, received one of the following: $\mathrm{BCG}, \mathrm{BCG}+5 \times 10^{7}$ killed Mycobacterium leprae, or $\mathrm{BCG}+6 \times 10^{8}$ killed $M$. leprae; 54,863 individuals found with a typical or a doubtful BCG scar received either placebo or BCG, or (from mid-1987 onwards) $\mathrm{BCG}+6 \times 10^{8}$ killed $M$. leprae. Side-effects were not looked for systematically, but 4 individuals self-reported with glandular abscesses, 9 with large postvaccination ulcers ( $>25 \mathrm{~mm}$ in diameter) and 2 with ulcers which persisted for more than 1 year.
\end{abstract}

\footnotetext{
${ }^{\circ}$ Current address: Universitats-Hautklinik 6650 Homburg/Saar, Germany.

- Reprint requests to Dr Fine.
} 
BCG vials collected from paraffin ref rigerators in the field showed satisfactory concentrations of viable BCG throughout the trial.

Post-vaccination skin test (RT23 and $M$. leprae soluble antigen) results and post-vaccination ulcer rates indicate that few mistakes were made in the field when recording the vaccine codes.

\section{Introduction}

There are currently 4 major trials under way to investigate the protective efficacy of different potential vaccines against leprosy. ${ }^{1,2.3 .4}$ Each of these trials has a unique design. All include BCG in at least 1 comparison group, but dosages and manufacturers differ and 3 trials, in Venezuela, Malawi and South India, include combined BCG plus killed M. leprae vaccines.

Taking into account previous experience with BCG trials against leprosy (and tuberculosis) it is expected that the results of the current trials will differ in various ways. ${ }^{5}$ In order to be able to interpret such differences as may arise, it is necessary to consider in detail the methods used in each trial. In this report we describe the procedures employed in the vaccination phase (1986-89) of the Karonga Prevention Trial (KPT), a leprosy and tuberculosis vaccine trial in Karonga District, Northern Malawi.

The Karonga Prevention Trial was designed to test the following hypotheses:

(i) adding killed $M$. leprae to $\mathrm{BCG}$ increases the protective efficacy of $\mathrm{BCG}$ vaccine against clinical leprosy; and

(ii) repeated $\mathrm{BCG}$ vaccination increases the protective efficacy of $\mathrm{BCG}$ vaccine against both clinical leprosy and tuberculosis.

\section{Methods}

HISTORICAL BACKGROUND

A longitudinal study of the epidemiology of leprosy, known as the LEPRA Evaluation Project (LEP), was initiated in Karonga District in 1979.6 The design of that study required 2 total population surveys in order to relate incident leprosy and tuberculosis cases discovered at the 2 nd survey to information on suspected risk factors collected at the 1st survey. After a pilot study in 1979, the first house-to-house survey was carried out from April 1980 to August 1984. It was then decided to combine the 2 nd survey of the LEP with the intake phase of a leprosy and tuberculosis vaccine trial. ${ }^{2}$

\section{Trial area}

Karonga District covers an area of 3346 sq. km along the north end of Lake Malawi (Figure 1). According to the preliminary report of the 1987 population and housing census the total population of Karonga District was 147,096 in September 1987. ${ }^{7}$ A small, hilly, sparsely populated section of Karonga District projecting into Chitipa District was omitted from the intake phase of the trial just as it had been from the 1 st total population survey of the LEP. ${ }^{6}$ Sensitization and dosage studies were carried out in $1984^{8}$ and at the 


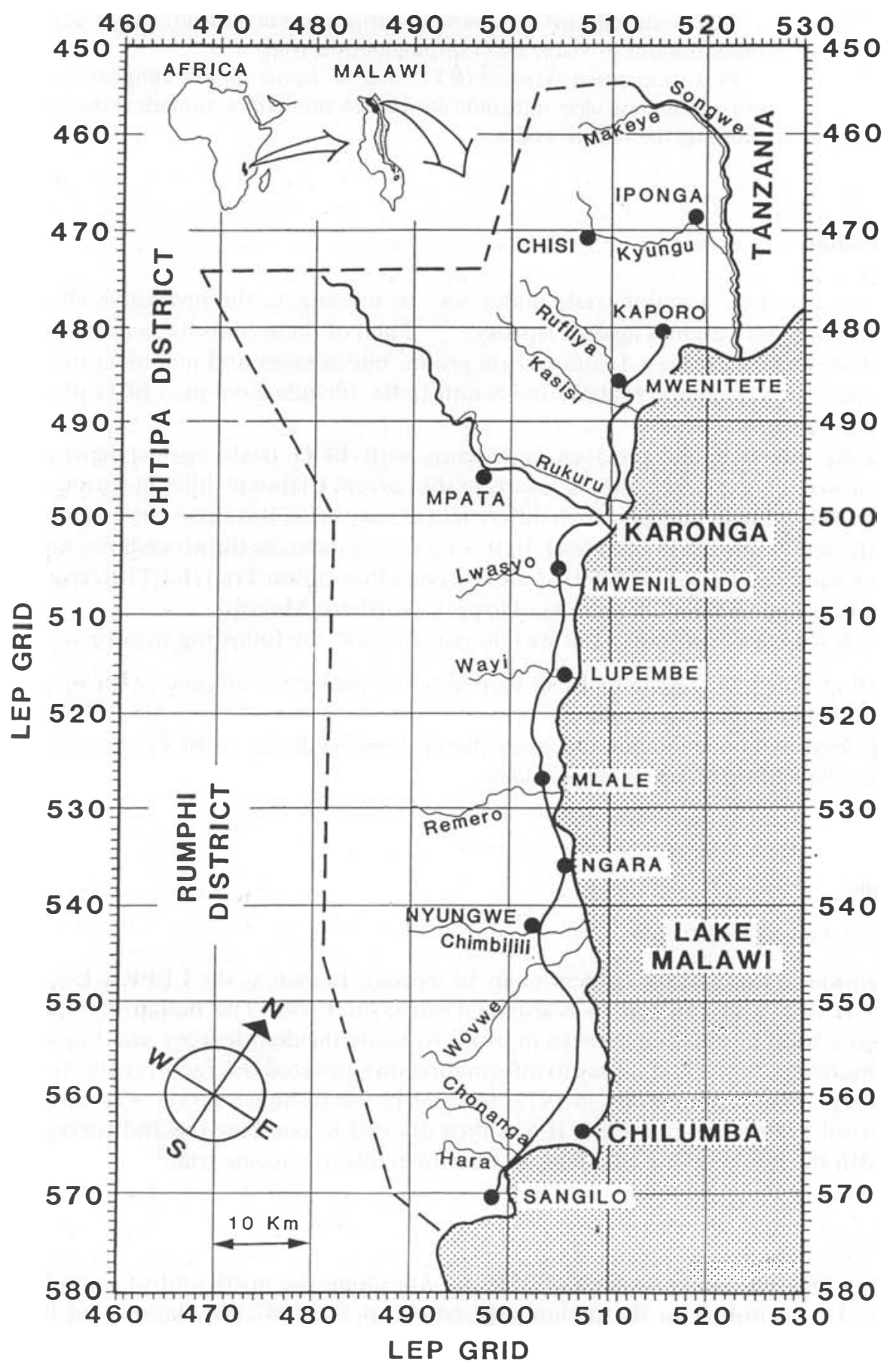

Figure 1. Map of Karonga District, Northern Malawi. Karonga is the administrative centre (the 'Boma') of the district. Headquarters of the Karonga Prevention Trial are in Chilumba. 
end of 1985 in several villages in the vicinity of Chilumba, the project headquarters, and so these villages were also not available for the main trial intake.

\section{Trial design}

The general design of the trial has been described elsewhere. ${ }^{2}$ People eligible for vaccination and who agreed to participate were divided according to their BCG scar status, which was determined at an examination by Leprosy Control Assistants (LCAs).

Individuals without a BCG scar were allocated to either

$$
\begin{aligned}
& \mathrm{BCG} \text { or } \\
& \mathrm{BCG}+5 \times 10^{7} \text { killed } M . \text { leprae or } \\
& \mathrm{BCG}+6 \times 10^{8} \text { killed } M . \text { leprae. }
\end{aligned}
$$

Thus all BCG scar negative individuals were given at least BCG. The BCG component of the scar negative vaccine was therefore labelled as such and only the dilutent (either water, or a suspension of $5 \times 10^{8}$, or $6 \times 10^{9}$ killed $M$. leprae $/ \mathrm{ml}$ ), which was supplied in brown vials, was code-labelled.

Individuals with a BCG scar, and those who BCG scar was considered doubtful by the LCAs (both called 'scar positives' hereafter), were, until mid-1987, given either BCG or a placebo. Therefore, for this group the dilutent was always water and the blind component of the vaccine was either BCG or dextran, provided as identical-looking freeze-dried pellets in identical-looking code-labelled vials. From mid-1987 onwards BCG $+6 \times 10^{9}$ killed $M$. leprae $/ \mathrm{ml}$ was added as a $3 \mathrm{rd}$ arm for BCG scar positive individuals. Scar positive individuals were thus allocated to receive either

$$
\begin{aligned}
& \text { placebo or } \\
& \text { BCG or } \\
& \text { BCG }+6 \times 10^{8} \text { killed } M \text {. leprae. }
\end{aligned}
$$

This made it necessary to match pellet and diluent so that no individual received killed $M$. leprae only (dextran pellet plus killed $M$. leprae diluent). Vaccines for scar-positive individuals were therefore supplied paired in small self-sealing plastic bags. This, incidentally, meant that BCG for scar positives was stored frozen (because it was paired with killed M. leprae bottles) from mid-1987 onwards, while BCG (labelled as such) for scar negative individuals continued to be stored at $+4 \mathrm{C}$ in solar refrigerators in Chilumba.

\section{Vaccines}

All BCG used in the trial was supplied free of charge by Glaxo. Lot numbers of BCG and dates of dispatch to Malawi are listed in Table 1. Further BCG lots were supplied by Evans from September 1989 onwards for the vaccination of babies born after the intake phase of the KPT had been completed (see below). BCG vials were collected from field refrigerators and taken to the $\mathrm{UK}$ for quality control whenever this was feasible, e.g. by the IMMLEP appointed trial monitors (initially MCP, later DC) during their visits. Quality control was carried out by Dr P. A. Jenkins at the Mycobacterium Reference Unit of the Public Health Laboratory Service, University Hospital of Wales, Cardiff.

$M$. leprae were derived from armadillos inoculated either with $M$. leprae direct from 
Table 1. BCG lot numbers used in the trial and their times of dispatch to Malawi

\begin{tabular}{lllr}
\hline Shipment & $\begin{array}{c}\text { Month and year of } \\
\text { dispatch }\end{array}$ & $\begin{array}{c}\text { Lot number } \\
\text { (manufacturer's number) }\end{array}$ & $\begin{array}{c}\text { Number of } \\
\text { (10-dose) vials }\end{array}$ \\
\hline 1 & December, 1985 & D752 & 720 \\
2 & March, 1986 & D763 & 720 \\
& Duly, 1986 & D747 & 65 \\
3 & November, 1986 & D763 & 1100 \\
4 & March, 1987 & D763C & 1200 \\
5 & August, 1987 & D763C & 1000 \\
6 & October, 1987 & D907 & 900 \\
7 & February, 1988 & D907 & 900 \\
8 & May, 1988 & D907 & 900 \\
9 & July, 1988 & D907 & 320 \\
10 & September, 1988 & D907 & 1000 \\
11 & January, 1989 & D1184 & 800 \\
12 & March, 1989 & D1184 & 1300 \\
13 & June, 1989 & D1188 & 800 \\
14 & August, 1989 & D1188 & 1000 \\
15 & & D1188 & 1000 \\
Total & & & 13725 \\
& & & \\
\hline
\end{tabular}

patients or-with $M$. leprae passaged not more than twice in other armadillos. The vaccine was prepared in licensed premises at Wellcome Laboratories (Beckenham, Kent, UK), under contract to IMMLEP and under supervision of the IMMLEP Bank. Only $M$. leprae-infected liver was used, this being the richest and most easily processed tissue. The livers chosen were sterile, free from cultivable mycobacteria and were exposed to $2 \cdot 5$ mega rad gamma radiation from a ${ }^{60} \mathrm{Co}$ source to ensure that all $M$. leprae were killed. Extraction and purification of $M$. leprae followed IMMLEP Protocol 1/79. ${ }^{9}$ Each $50 \mathrm{~g}$ liver preparation yielded approximately $10 \mathrm{ml}$ suspension of purified $M$. leprae, from which $0.5 \mathrm{ml}$ was used for a quantitative and qualitative assessment of its suitability for vaccine use. From time to time preparations were pooled into lots as required to sustain the trial. After the volume and density of the lot was determined it was diluted with $0.01 \%$ Tween $80 /$ phosphate-buffered saline to the concentration required for the trial (i.e. $5 \times 10^{8}$ and $6 \times 10^{9} \mathrm{AFB} / \mathrm{ml}$ ). These suspensions were aliquoted in $1 \cdot 1 \mathrm{ml}$ quantities into $4 \mathrm{ml}$ rubber capped brown bottles, sealed, autoclaved at $120^{\circ} \mathrm{C}$ for 20 minutes and stored at $-70^{\circ} \mathrm{C}$.

In all, 3 lots of vaccine (II-IV) were required for the trial in Malawi. Lot II was also used in the leprosy vaccine trial in Venezuela and the remainder of Lot IV will be used in the trial in South India.

All vaccines except BCG vials labelled as such were sent to Malawi on dry ice. BCG vials were usually shipped on wet ice.

\section{Randomization}

All vaccine vials were coded by the IMMLEP-appointed trial monitors (MCP, DC). The code included a check letter to enable the identification of key punch errors at the time of data entry. In addition, the range of code numbers was different for scar-positive and scar- 
negative vaccines. This helped quality control in Chilumba because data entry programs did not permit routine entry of records with a discrepancy between BCG scar status and type of vaccine given. Such records could only be entered by making use of a password.

As multi-dose vials were used, most vaccine codes apply to several (up to 11) individual recipients from the same vial.

\section{Field organization}

Initially 5 teams (later increased to 6 and, towards the end of the intake phase, 7) operated in the field. Each field team was composed of 1 interviewer, 2 or 3 LCAs and 2 vaccinators. A cook was employed for each team at their camp. In addition a villager, usually a relative of the village headman or someone recommended by him, was employed as a 'motivator' to remind people the previous evening that the team would visit them the following day according to prior arrangements.

Interviewers carried A5 size computer print-outs ('field tickets') for all individuals found during the 1 st total population survey in a particular village. After identifying an individual the interviewers either completed the field ticket for that person (and made corrections to the print-out if necessary) or filled a new personal form if no field ticket was available because, for example, the person was new in this village. Anyone vaccinated previously in the trial was meant to be excluded from (another) vaccination by the interviewers (see Figure 2). Interviewers also looked for tuberculosis cases, and sputum specimens were collected from anyone who reported a productive cough of more than 3 weeks' duration. Specimens were stored at $4-10^{\circ} \mathrm{C}$ in the camp refrigerators before being sent to the project laboratory in Chilumba every week.

Until the end of 1985 sputum specimens were examined only by microscopy in Chilumba. M. tuberculosis culture facilities were introduced in Chilumba early in 1986, in collaboration with the Mycobacterium Reference Unit of the Public Health Laboratory Service, in Cardiff. Details will be described separately.

Usually people were first interviewed and then, during a thorough examination for any signs of leprosy, LCAs decided whether or not an individual was still eligible for vaccination (Figure 2). LCAs were meant to exclude known leprosy patients, leprosy suspects, malnourished individuals, in particular malnourished children, and anyone else seriously ill. Individuals born before 1914 and visitors from outside Karonga District were only vaccinated at their request. They were not encouraged to come forward for vaccination. Similarly, babies who were under 3 months old were only vaccinated at the request of their parents, otherwise they were not included in the trial. Children with an acute febrile illness, for example malaria or measles, were vaccinated after they had recovered.

Each team had a paraffin ref rigerator and 2 spare paraffin refrigerators were kept at headquarters. BCG vaccines for scar-negative individuals, and, until mid-1987, the pellets and diluent for scar-positive individuals, were stored in the cold compartment $\left(4 \mathrm{C}-10^{\circ} \mathrm{C}\right.$ depending on the time of the year). Dilutent for scar-negative individuals and vaccines for scar-positives from mid-1987 onwards were stored in the freezer compartment. Vaccines were supplied to the teams from Chilumba on a weekly basis. They were delivered in vaccine carriers ('Thermos' vaccine carrier class B, model 3504/38). Once vials had thawed, they were not put back into the freezer compartments. 


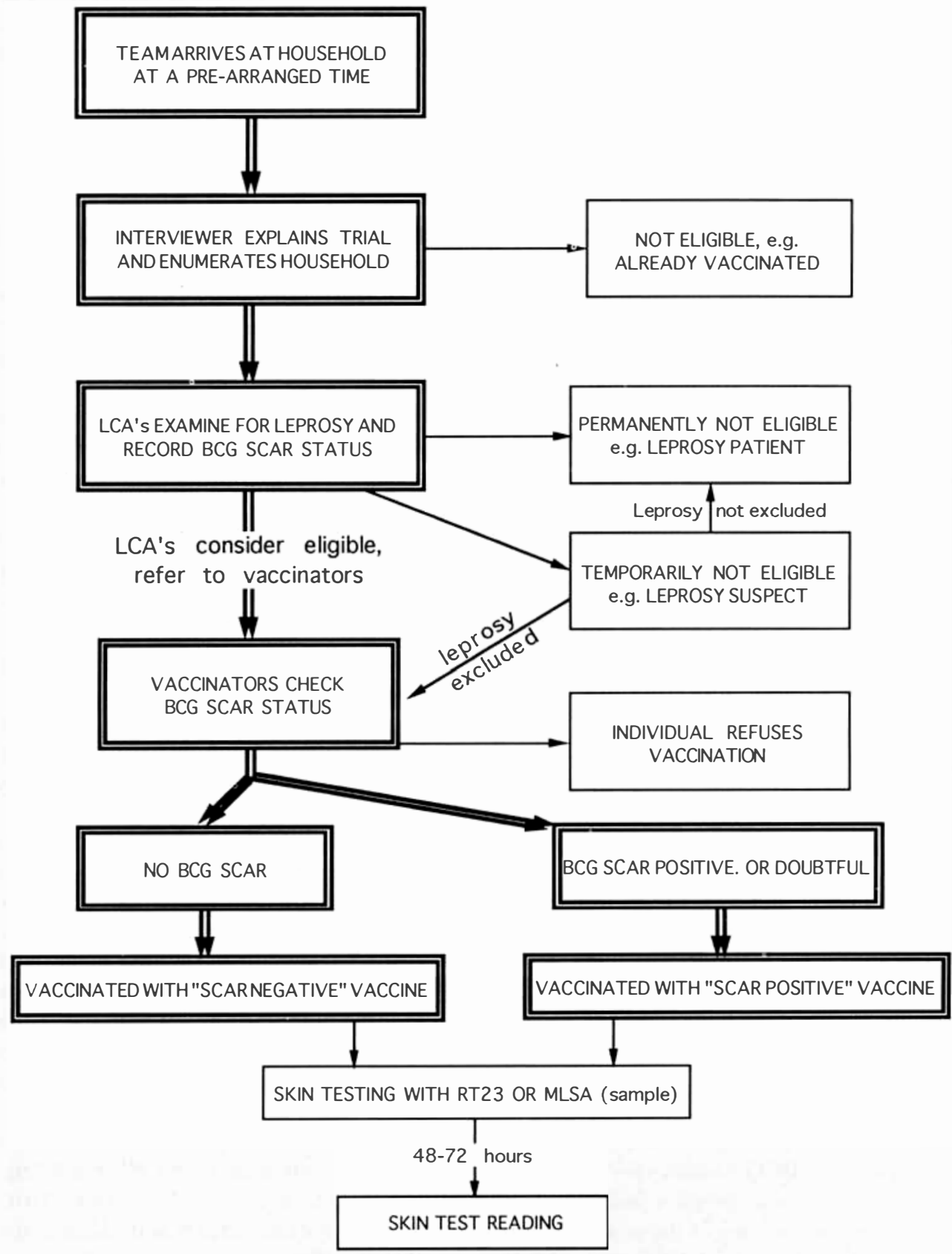

Figure 2. Field activities during the recruitment phase of the Karonga Prevention Trial, 1986-89. 
At the beginning of the trial each vaccine code was copied by the vaccinators from the vial used onto the vaccinated individual's examination form. However, it was soon realized that vaccinators sometimes either forgot to write down the codes or made errors when copying. Double entry of codes into registers did not entirely solve the problem. The vaccines were therefore packed with 10 preprinted labels which the vaccinators only had to stick onto the examination forms after vaccination.

The vaccinators carried the vaccines to the field in wide-mouthed Thermos flasks containing ice cubes. They reconstituted the vaccines after arriving at the first household scheduled for examination and vaccination each day. For BCG scar negatives the BCG vial was put into a black sleeve, opened, and the BCG was suspended in $1 \mathrm{ml}$ diluent which had been drawn with a tuberculin syringe from the next brown vial in the Thermos flask. Initially the same tuberculin syringe was also used for injection, being sterilized by flaming after each injection of $0 \cdot 1 \mathrm{ml}$ vaccine. As some vaccine had to be squirted out after flaming the needle, only 8 or 9 doses were obtained from each $1 \mathrm{ml}$ vial of vaccine. Both the syringe and the needle were discarded after the contents of the syringe had been finished. During the latter half of 1987 , sterilizable $0.1 \mathrm{ml}$ syringes and needles were introduced, following a recommendation by the trial monitor and the Leprosy Unit of the WHO. This meant that the reconstituted BCG had to be re-injected into the brown diluent vial and drawn up 1 dose at a time. Because all of the $1 \cdot 1 \mathrm{ml}$ diluent was now used to reconstitute the $1 \mathrm{mg} \mathrm{BCG}$ this meant that vaccinees received on average only $0.09 \mathrm{mg}$ BCG rather than $0 \cdot 1 \mathrm{mg}$ as previously. A separate syringe and needle were used for each vaccinee. Needles and syringes were steam-sterilized at the end of each day at the camp following standard EPI procedures. ${ }^{10}$

For BCG scar positives the process was similar until mid-1987, but from then on vaccinators had to be careful to use pellet and diluent as matched. They were instructed to compare labels on the powder and diluent carefully and to be sure that the code numbers were identical and the same as those on the spare labels provided for the forms.

Vaccinators were net allowed to reconstitute the next vial of scar-negative or scarpositive vaccine until the last vial had been completely finished. There were strict instructions to tear up any unused labels after each vial was finished. Reconstituted vaccines not used by the end of the day were discarded. To further minimize confusion, vaccinators not only used differently coloured flasks for scar-negative and scar-positive vaccines but were also given red nail varnish to mark vials and syringes for scar-positive vaccines. The colour coding extended to labels - those for scar-positive vaccines were pink, and those for scar-negative vaccines were white.

Vaccinators were trained for 2-3 months before they were allowed to vaccinate. During the training period they injected $0.1 \mathrm{ml}$ skin test reagents, RT23 tuberculin or $M$. leprae soluble antigen preparations, intracutaneously in the volar surface of the forearm. The tuberculin (RT23, 2IU per $0 \cdot 1 \mathrm{ml}$ dose) was purchased from the Statens Serum Institute, Copenhagen, Deninark. M. leprae soluble antigen skin test reagents were prepared at the National Institute of Medical Research, London. ${ }^{11}$ Skin test induration sizes were read on the 2 nd or 3 rd day after injection. Induration diameters were measured along and across the arm and both numbers were recorded, although only the mean diameter was coded. In some areas vaccinators collected fingerprick blood specimens, dried on chromatography paper, instead of carrying out skin tests. A full analysis of skin test and serology results, before and after vaccination, will be published separately.

All vaccines were injected intradermally in to the right deltoid region, the area used for 
BCG vaccination in Malawi. A different site was chosen only in exceptional circumstances e.g. the volar side of the left forearm.

The vaccinators tried to persuade all eligible individuals to agree to vaccination. People were concerned mostly about ulcers, particularly whether they might hinder them when it was time to plant, weed or harvest. It was explained to people that the purpose of the trial was to find a vaccine against leprosy, and that everyone who developed an ulcer would benefit to some degree from the vaccination, but that some of the vaccines we were using might be stronger than others. Initially public meetings were held to explain our work, but village headmen soon said that people knew all about us and that there was no need for further meetings. Village headmen and elders were always briefed before a team moved into their area.

People were not reviewed routinely for side effects after vaccination but were encouraged to self-report to a team if they had any untoward reaction.

Several times during the intake phase the vaccinators were required to measure vaccine ulcers in individuals vaccinated 4 weeks previously. This involved removal of the scab with an alcohol swab and measurement of the inner diameters of the ulcer along and across the arm. The mean diameter was coded and used for analysis. All ulcers on the right deltoid area were assumed to be attributable to the vaccination, even if they did not look like typical vaccine ulcers. No history was taken by the vaccinators when measuring ulcers. Ulcer sizes recorded by one particular vaccinator were excluded from the analysis after it was discovered that some of his results were invented and not based on actual measurements.

\section{Health centre hased activities}

Towards the end of the trial intake phase vaccinators were also posted to various rural health centres and to the district hospital in Karonga. They vaccinated babies attending the under-5s clinics who had been born or who had arrived with their families after a field team had been in their village. In addition, these vaccinators also collected sputum specimens from anyone self-reporting with a productive cough of more than 3 weeks' duration (as done by the interviewers in the field).

Vaccinators at the health centres were supplied with up-to-date computer print-outs of all children already vaccinated in the trial, in order to avoid accidental re-vaccination of children. In cases of doubt the vaccinators contacted project headquarters to find out whether or not a particular child had already been vaccinated. Up to June 1990 the vaccinators used Glaxo BCG alone for babies under 3-months-old, but randomized 'scar negative' vaccines for those over 3-months-old. From June 1990 onwards the vaccinators used Glaxo/Evans BCG for every child. Irrespective of age the infants received $0 \cdot 1 \mathrm{ml}$ vaccine in the right deltoid area.

\section{Data processing}

All general examination forms and household and personal questionnaires were coded, checked and entered on Burroughs B26 microcomputers in Chilumba. Entry programs, written in COBOL, contained a large number of range and consistency checks and some variables were entered twice on different screens. However, the systematic double entry of all questionnaires and examination forms was not attempted because it was thought that 
Table 2. Numbers of individuals vaccinated once during the intake phase of the leprosy vaccine trial in Karonga District by age, sex and type of vaccine. One individual vaccinated but with an unknown year of birth has been excluded from this table

\begin{tabular}{|c|c|c|c|c|c|}
\hline \multirow{2}{*}{$\begin{array}{l}\text { Age at } \\
\text { vaccination }\end{array}$} & \multicolumn{2}{|c|}{ Scar-negative vaccine } & \multicolumn{2}{|c|}{ Scar-positive vaccine } & \multirow[b]{2}{*}{ Total } \\
\hline & Males & Females & Males & Females & \\
\hline$<5$ & 6562 & 6619 & 3525 & 3312 & 20018 \\
\hline $5-14$ & 7716 & 8006 & 11949 & 11232 & 38903 \\
\hline $15-24$ & 3739 & 4193 & 6703 & 7277 & 21912 \\
\hline $25-34$ & 2304 & 4369 & 3257 & 3622 & 13552 \\
\hline $35-54$ & 6548 & 8602 & 1189 & 1769 & 18108 \\
\hline$\geq 55$ & 3862 & 3625 & 538 & 490 & 8515 \\
\hline Total & 30731 & 35414 & 27161 & 27702 & 121008 \\
\hline
\end{tabular}

this would make the data handling procedures too cumbersome. Approximately every month all complete data were copied onto floppy disks: 1 set of disks was sent to London, and 1 was retained in Chilumba while deleting the data from the hard disks. In comparison with the procedures used during the 1 st total population survey, ${ }^{6}$ the entry of data in Chilumba had many advantages. In particular, entry and check programs could easily be updated when new variables or codes were introduced. Local data entry also facilitated verification of information rejected by the check programs at the time of data entry. As during the first total population survey, details of leprosy and tuberculosis patients and serology results were coded on special forms and sent to London for entry.

In London all data were transferred to the Amdahl mainframe of the University of London Computer Centre.

\section{Analysis}

We here present data on the numbers of people who were vaccinated, the numbers who were eligible but refused vaccination and the numbers not eligible. For individuals seen more than once the first recorded reason for refusal or non-eligibility is used, except in the case of leprosy suspects for whom the reason for non-eligibility is taken from the 'review examination' form filled in by a medical officer. All analyses requiring the breaking of the vaccine codes were and are carried out by the trial monitors (MCP, DC).

All babies vaccinated at the under-5s clinics are excluded from the following analyses irrespective of the type of vaccine they received. In so far as they were brought to the health centres they are different from the babies recruited at their homes, and thus it is less appropriate to calculate refusal rates for them. Also excluded from the analyses are 298 individuals who were accidentally vaccinated twice and 2 who were vaccinated 3 times.

\section{Results}

TRIAL POPULATION

Table 2 shows the numbers of individuals who were vaccinated once during the main intake phase by age, sex and type of vaccine they received. The total number of people 
Table 3. Numbers of individuals ineligible for vaccination during the intake phase of the leprosy vaccine trial in Karonga District by reason and by age

\begin{tabular}{|c|c|c|c|c|c|c|c|}
\hline \multirow[b]{2}{*}{ Ag. } & \multicolumn{6}{|c|}{ Reason for non-eligibility at first examination } & \multirow[b]{2}{*}{ Total } \\
\hline & $\begin{array}{l}\text { Age }<3 \\
\text { months }\end{array}$ & Malnutrition & $\begin{array}{l}\text { Seriously } \\
\text { sick }\end{array}$ & $\begin{array}{l}\text { Born } \\
<1914\end{array}$ & Leprosy & $\begin{array}{c}\text { 'Already } \\
\text { vaccinated*" }\end{array}$ & \\
\hline$<5$ & 657 & 425 & 167 & - & 0 & 3 & 1252 \\
\hline $5-14$ & - & 51 & 93 & - & 141 & 7 & 292 \\
\hline $15-24$ & - & 1 & 54 & - & 407 & 13 & 475 \\
\hline $25-34$ & - & 0 & 47 & - & 445 & 7 & 499 \\
\hline $35-54$ & - & 0 & 78 & - & 985 & 5 & 1068 \\
\hline$>54$ & - & 2 & 149 & 1339 & 674 & 7 & 2171 \\
\hline Total & $657(11 \cdot 4) \dagger$ & $479(8 \cdot 3)$ & $588(10 \cdot 2)$ & $1339(23 \cdot 3)$ & $2652(46 \cdot 1)$ & $42(0 \cdot 7)$ & $5757(100)$ \\
\hline
\end{tabular}

* Wrongly assumed to have already been vaccinated by another team in another village.

$\dagger$ Numbers in parentheses are percentages.

recruited into the trial was 121,008 , of whom 66,145 received 'scar-negative' and 54,863 'scar positive' vaccines. One individual who was vaccinated but whose year of birth was not recorded has been excluded from this table.

Table 3 shows the distribution by age of the 6 different reasons why 5757 individuals were considered ineligible for vaccination. One individual whose year of birth was not recorded is excluded from this table. Of the 5757 ineligible individuals 3177 (55\%) were female and $2580(45 \%)$ male. The interviewers were persuaded by 42 individuals that they had been vaccinated earlier in some other village and by the time it was discovered that they had not it was no longer practical to go back to their households to vaccinate them. We excluded 2652 (46\%) ineligible individuals because of a history of leprosy, residual signs of leprosy, active leprosy or a suspicion of leprosy even if not confirmed. Although a history of leprosy was a reason for ineligibility, we identified 280 individuals with a history of leprosy but without residual signs who were accidentally vaccinated because they did not mention to the LCAs that they had once received or were receiving anti-leprosy treatment. In general their histories were only discovered in the office long after they had been vaccinated. A mild type-1 reaction developed in a previously treated patient soon after vaccination.

Tables 4a and 4b show the reasons why 3132 females and 2703 males refused vaccination. Vimbuza is the local term for a condition in which the individual is "possessed by spirits'. In general these spirits do not allow the person they possess to receive any injection. If someone possessed by spirits is given an injection a violent attack may result, usually taking the form of guttural cries, associated with uncontrollable jerking of the body, and sometimes followed by a period of loss of consciousness. Vimbuza is known to be more common among females than males ${ }^{12}$ and this is apparent from Tables $4 \mathrm{a}$ and $4 \mathrm{~b}$. Vimbuza was cited as the reason for refusal by $35 \cdot 2 \%$ (1104/3132) female refusers but by only $19 \cdot 2 \%(519 / 2703)$ of male refusers. The term 'vimbuza' also includes 'mitima', 'mizimi', 'visilisi' and 'chikoko', although the terms have somewhat different meanings. 'Visilisi' are particularly violent spirits while the term 'chikoko' when used for children often means a history of febrile convulsions rather than possessions by spirits. Also 90 members of fundamentalist religious communities, in particular the St Michael's Church, 
Table 4a. Number of females who refused vaccination during the intake phase of the leprosy vaccine trial in Karonga District by age and reason given (if any)

\begin{tabular}{|c|c|c|c|c|c|c|}
\hline \multirow[b]{2}{*}{ Age } & \multicolumn{5}{|c|}{ Reason for refusal to be vaccinated (if any) } & \multirow[b]{2}{*}{ Total } \\
\hline & Vimbuza & Religious & $\begin{array}{l}\text { Mentally } \\
\text { ill }\end{array}$ & Others & $\begin{array}{c}\text { No } \\
\text { reason* }\end{array}$ & \\
\hline$<5$ & 103 (chikoko) & 1 & 0 & 12 & 272 & 388 \\
\hline $5-14$ & 87 & 8 & 1 & 4 & 176 & 276 \\
\hline $15-24$ & 138 & 9 & 6 & 6 & 420 & 579 \\
\hline $25-34$ & 166 & 3 & 8 & 3 & 328 & 508 \\
\hline $35-54$ & 396 & 6 & 6 & 17 & 423 & 848 \\
\hline$\geq 55$ & 214 & 3 & 3 & 15 & 298 & 533 \\
\hline Total & $1104(35 \cdot 3) \dagger$ & $30(1 \cdot 0)$ & $24(0 \cdot 8)$ & $57(1 \cdot 8)$ & $1917(61 \cdot 2)$ & $3132(100)$ \\
\hline
\end{tabular}

* Individuals who refused to be vaccinated without giving a reason.

$\dagger$ Numbers in parentheses are percentages.

Table 4b. Number of males who refused vaccination during the intake phase of the leprosy vaccine trial in Karonga District by age and reason given (if any)

\begin{tabular}{|c|c|c|c|c|c|c|}
\hline \multirow[b]{2}{*}{ Age } & \multicolumn{5}{|c|}{ Reasons for refusal to be vaccinated (if any) } & \multirow[b]{2}{*}{ Total } \\
\hline & Vimbuza & Religious & $\begin{array}{c}\text { Mentally } \\
\text { ill }\end{array}$ & Others & $\begin{array}{l}\text { No } \\
\text { reason* }\end{array}$ & \\
\hline$<5$ & 110 (chikoko) & 11 & 1 & 6 & 245 & 373 \\
\hline $5-14$ & 84 & 14 & 5 & 14 & 199 & 316 \\
\hline $15-24$ & 78 & 8 & 6 & 8 & 424 & 524 \\
\hline $25-34$ & 80 & 8 & 9 & 10 & 493 & 600 \\
\hline $35-54$ & 122 & 14 & 8 & 8 & 448 & 600 \\
\hline$\geq 55$ & 45 & 5 & 3 & 8 & 229 & 290 \\
\hline Total & $519(19 \cdot 2) \dagger$ & $60(2 \cdot 2)$ & $32(1 \cdot 2)$ & $54(2 \cdot 0)$ & $2038(75 \cdot 4)$ & $2703(100)$ \\
\hline
\end{tabular}

* Individuals who refused to be vaccinated without giving a reason.

$\dagger$ Numbers in parentheses are percentages.

refused vaccination. This may be an underestimate because members of the St Michael Church were generally unco-operative and we may have under-recorded their number. 'Others' stands for a variety of reasons, such as fear of keloid scars. We could have recorded the 56 severely mentally ill individuals as 'ineligible', since they were not able to give consent. Although 3955 individuals refused vaccination, simply stating that they did not want to be vaccinated.

\section{QUALITY CONTROL MEASUREMENTS}

Figures $3 \mathrm{a}$ and $3 \mathrm{~b}$ show relative frequency distributions of diameters of 1499 ulcers among scar-negative and scar-positive individuals broken down by vaccine type. The 


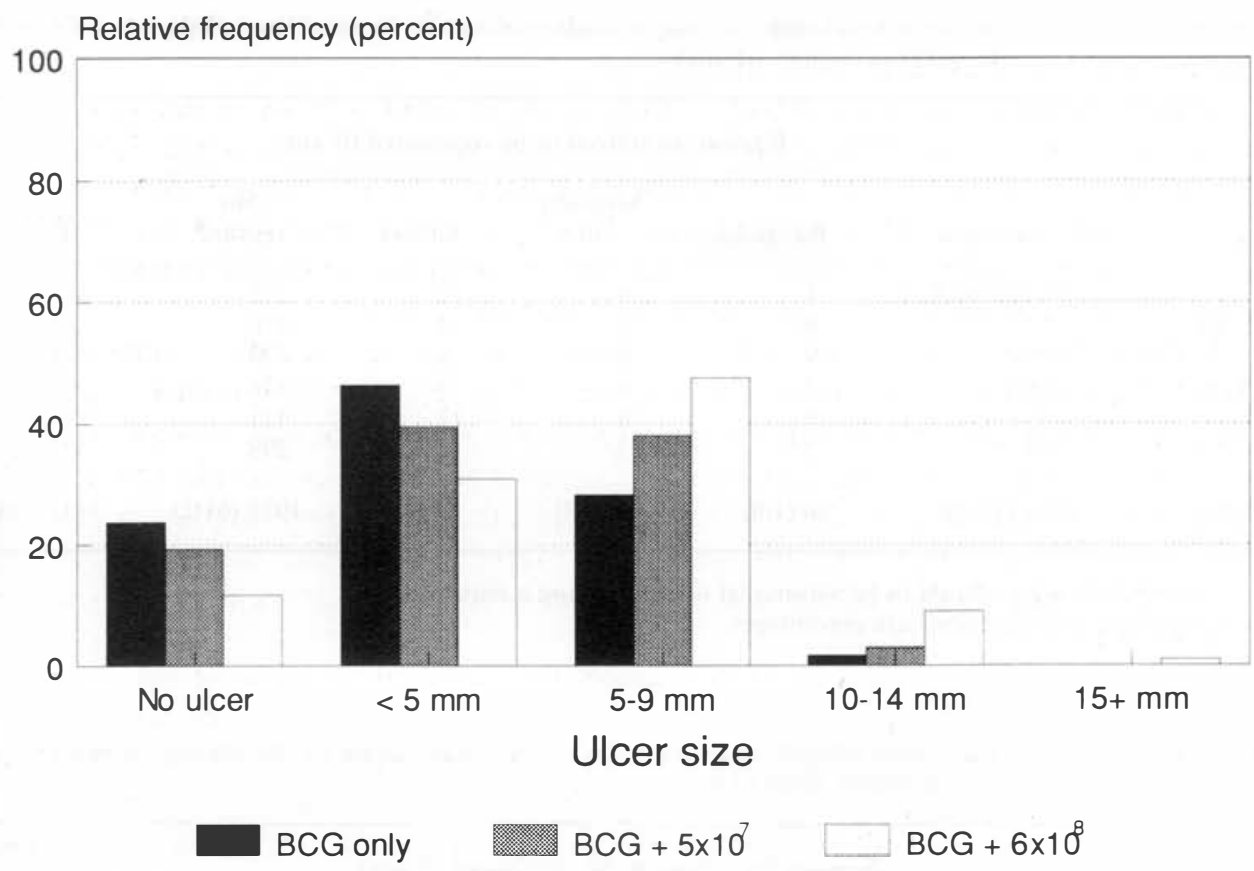

Figure 3(a). Ulcer sizes in BCG scar-negative individuals 4 weeks after vaccination, by type of vaccine given. All 794 vaccinees received at least $\mathrm{BCG}$.

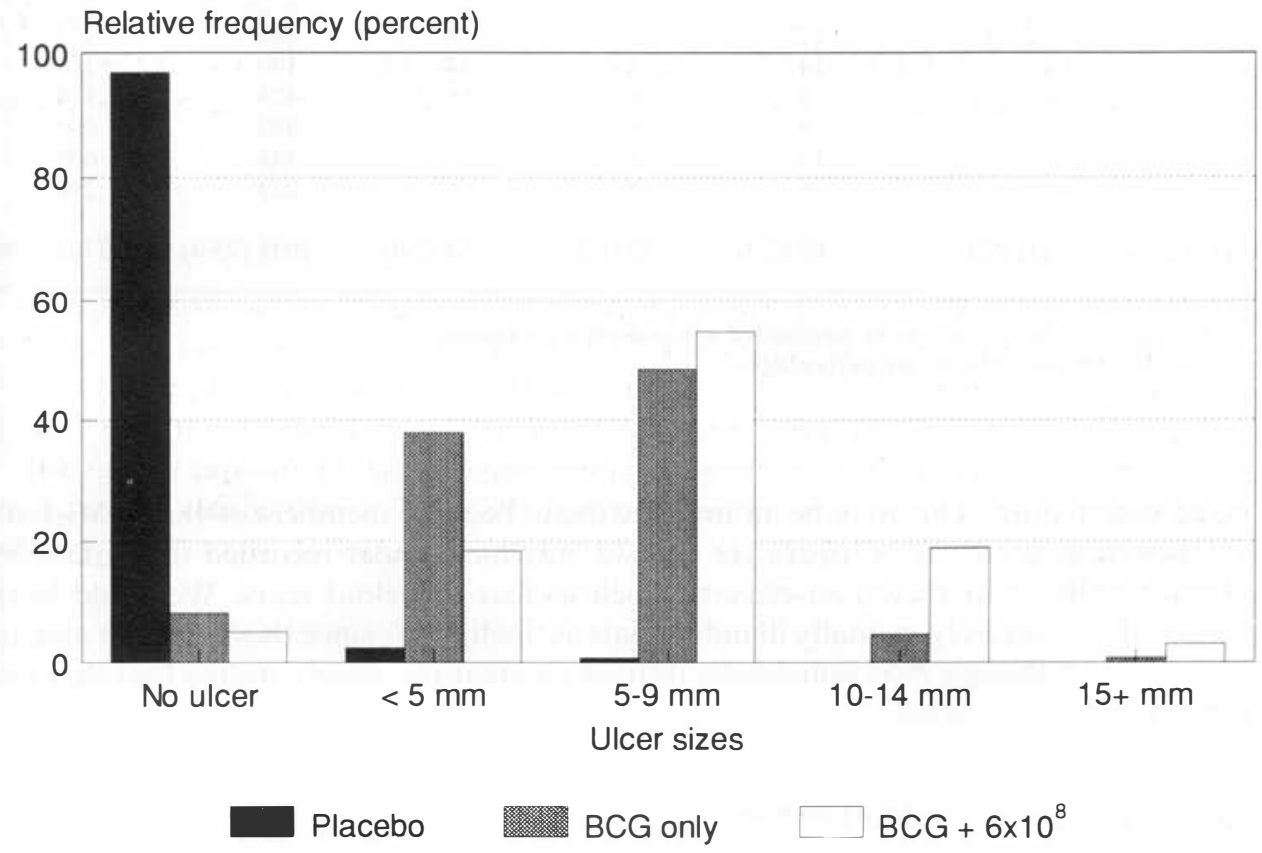

Figure 3(b). Ulcer sizes in BCG scar-positive individuals (including those whose 'BCG' scar was considered doubtful) 4 weeks after vaccination, by type of vaccine given. Of the 705 vaccinees 248 received placebo only. 
average ulcer size increased with increasing the dose of killed $M$. leprae. Age and sex had little influence on these ulcer sizes (not shown).

Figures $4 \mathrm{a}$ and $4 \mathrm{~b}$ show cumulative frequencies of ulcer sizes by initial scar status. Among scar negatives, ulcers over $10 \mathrm{~mm}$ in diameter were observed in $1.0 \%(3 / 291)$ who were given BCG only, $2 \cdot 5 \%(5 / 202)$ of those given BCG $+5 \times 10^{7}$ and in $5 \cdot 0 \%(15 / 301)$ of those given $\mathrm{BCG}+6 \times 10^{8}$ killed $M$. leprae. Among BCG scar positives $3 \cdot 5 \%(9 / 256)$ of those given $\mathrm{BCG}$ only were found with an ulcer over $10 \mathrm{~mm}$ in diameter compared to $14.9 \%(30 / 201)$ of those given $\mathrm{BCG}+6 \times 10^{8}$ killed M. leprae.

Table 5 shows skin test results from 433 vaccinees tested with RT23 tuberculin or MLSA (batch CD19) at the time of vaccination and approximately 3 months thereafter. The average increase in tuberculin sensitivity was similar among all groups receiving BCG, with or without killed $M$. leprae. On the other hand, the increase in sensitivity to CD19 was correlated with the concentration of killed $M$. leprae in the vaccine. Of particular relevance (for the purpose of this paper) is the fact that there was no appreciable change in the average skin test induration sizes among vaccinees who received placebo only.

According to the records, 63 BCG scar-negative individuals received 'scar-positive' vaccine. In addition, 39 individuals with a definite BCG scar, and 44 individuals with a doubtful BCG scar, were mistakenly given 'scar-negative' vaccine. In addition the BCG scar status was not recorded for 7 vaccinees. There are 3 possible explanations for the discrepancies between BCG scar status and type of vaccine given: (i) an appropriate vaccine was given but the scar was wrongly recorded; (ii) an appropriate vaccine was given but the wrong label was attached to the individual's General Examination Form; or (iii) an inappropriate vaccine was indeed given.

During the intake phase of the KPT, 57 vials of BCG were taken back to the UK for quality control assessment. Figure 5 shows the distribution of counts of viable BCG per vial. The counts range from $2.5 \times 10^{6}$ to $1 \times 10^{8}$ viable BCG per vial. The median count was $2 \cdot 4 \times 10^{7}$.

\section{ADVERSE REACTIONS}

Apart from large ( $>10 \mathrm{~mm}$ ) ulcers (see Figures 3a, 3b, 4a and $4 \mathrm{~b}$ ), a few other side effects were observed or brought to the attention of the project staff. These included glandular abscesses (4), exceedingly large ( $>25 \mathrm{~mm}$ ) ulcers (9) and ulcers persisting more than 1 year (2). There was 1 hypersensitivity reaction probably attributable to dextran in a BCG scar-positive child. ${ }^{13}$ In addition, there was an unexplained series of multiple though small vaccine ulcers which caused some concern in mid-1986. A few individuals informed us that they had gone to Karonga District Hospital because of side-effects of the vaccinations but their records could not be traced.

\section{Discussion}

We emphasize here issues related to the allocation of the vaccines in the field and to quality control of the vaccines.

There is evidence that BCG vials collected from the paraffin ref rigerators in the field contained satisfactory numbers of viable BCG. All 57 vials which were sent for quality 


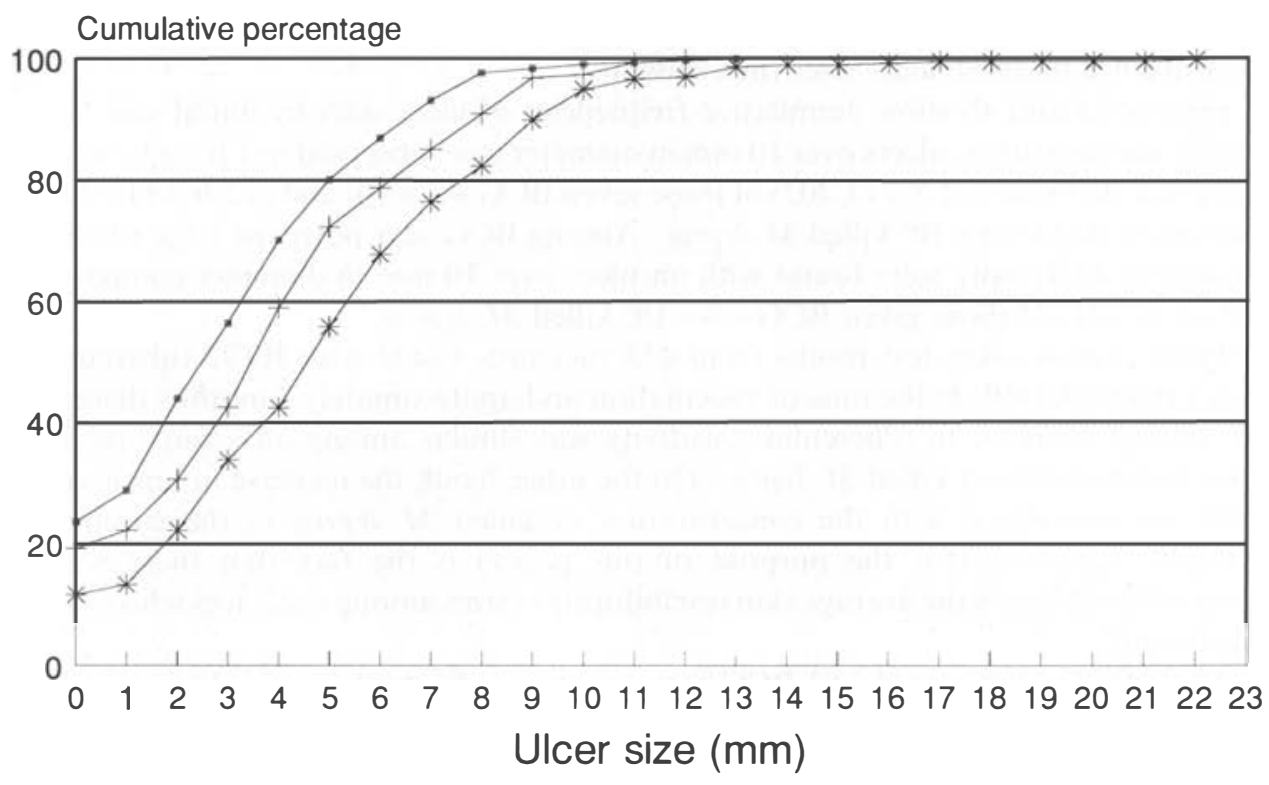

$$
\because \mathrm{BCG} \text { only } \quad \mathrm{BCG}+5 \times 10^{7} \rightarrow \mathrm{BCG}+6 \times 10^{8}
$$

Figure 4(a). Cumulative frequency of ulcer sizes in BCG scar-negative individuals 4 weeks after vaccination, by type of vaccine given. All 794 vaccinees received at least BCG.

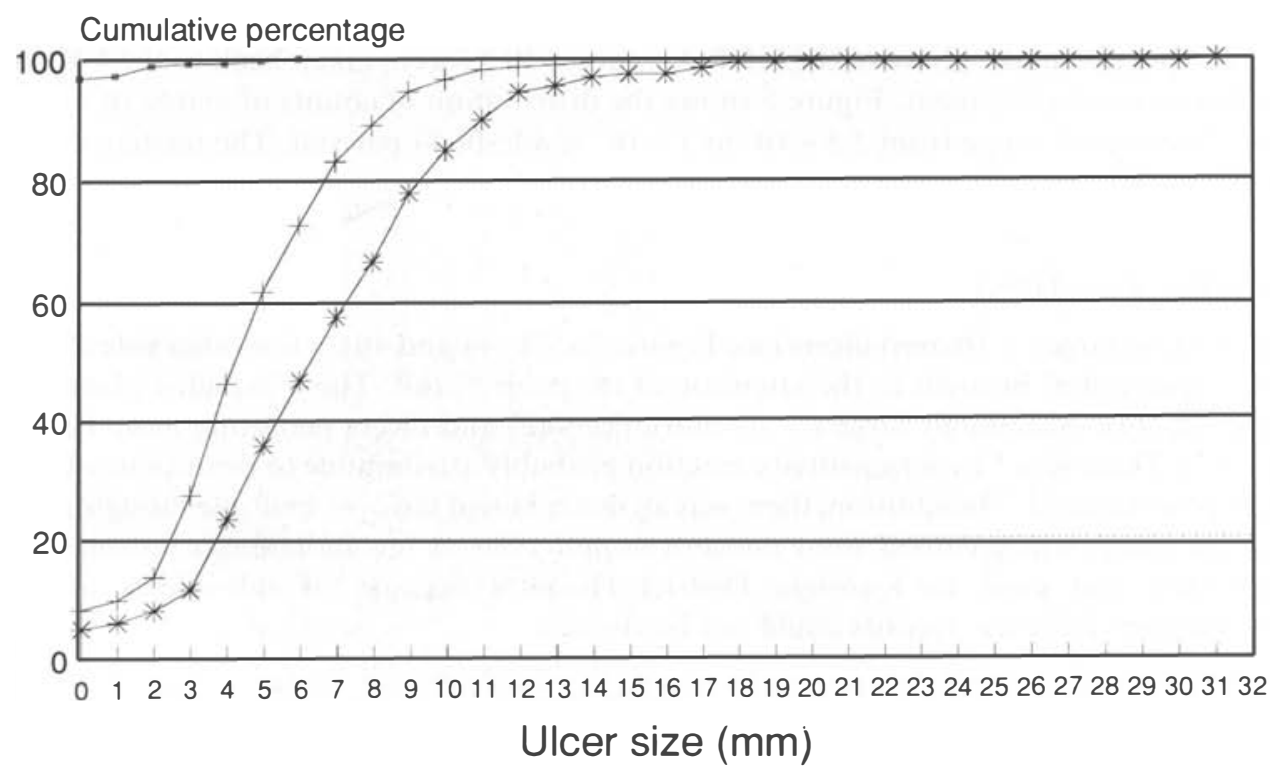

\section{Placebo \\ BCG only \\ $* \mathrm{BCG}+6 \times 10^{8}$}

Figure 4(b). Cumulative frequency of ulcer sizes in BCG scar positive individuals (including those whose 'BCG' scar was considered doubtful) 4 weeks after vaccination, by type of vaccine given. Of the 705 vaccinees 248 received placebo only. 
Table 5. Pre- and post-vaccination skin test results (average induration diameter) in 433 vaccinees tested in 1987 (before the introduction of the $3 \mathrm{rd}$ arm among BCG scar positives). RT23= batch number of Statens Serum Institute tuberculin, $\mathrm{CD} 19=$ batch number of $M$. leprae soluble antigen skin test reagent used. $\mathrm{KMl}=\mathrm{Killed}$ M. leprae

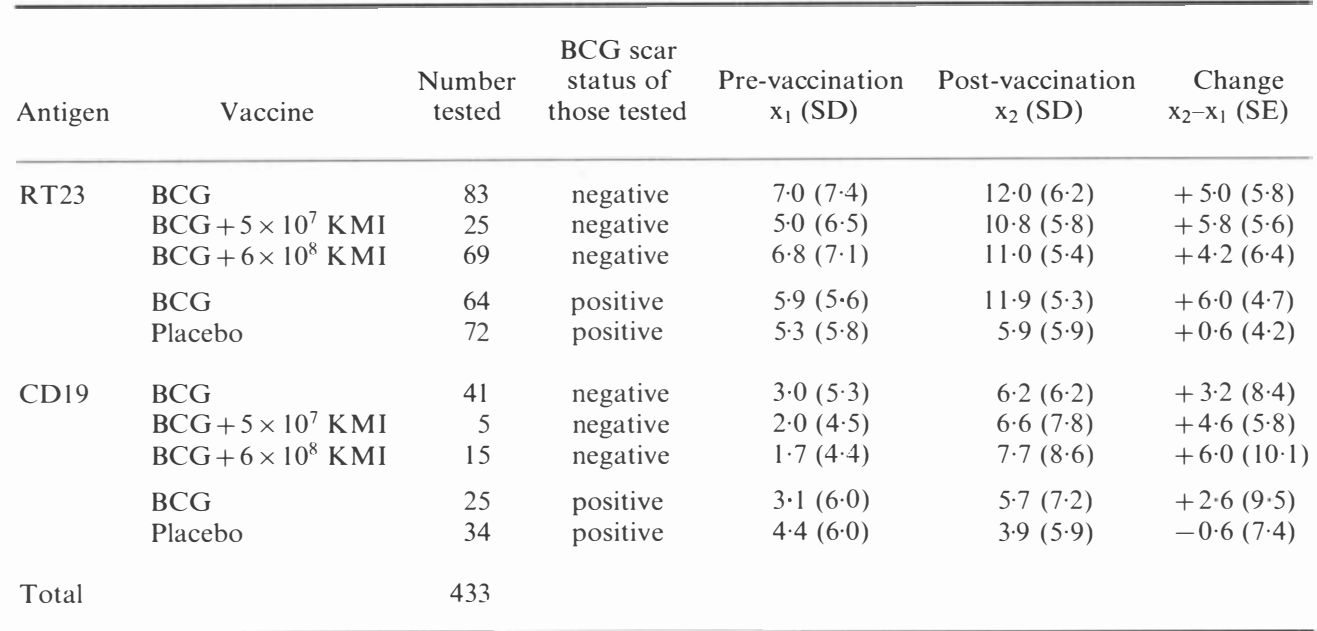

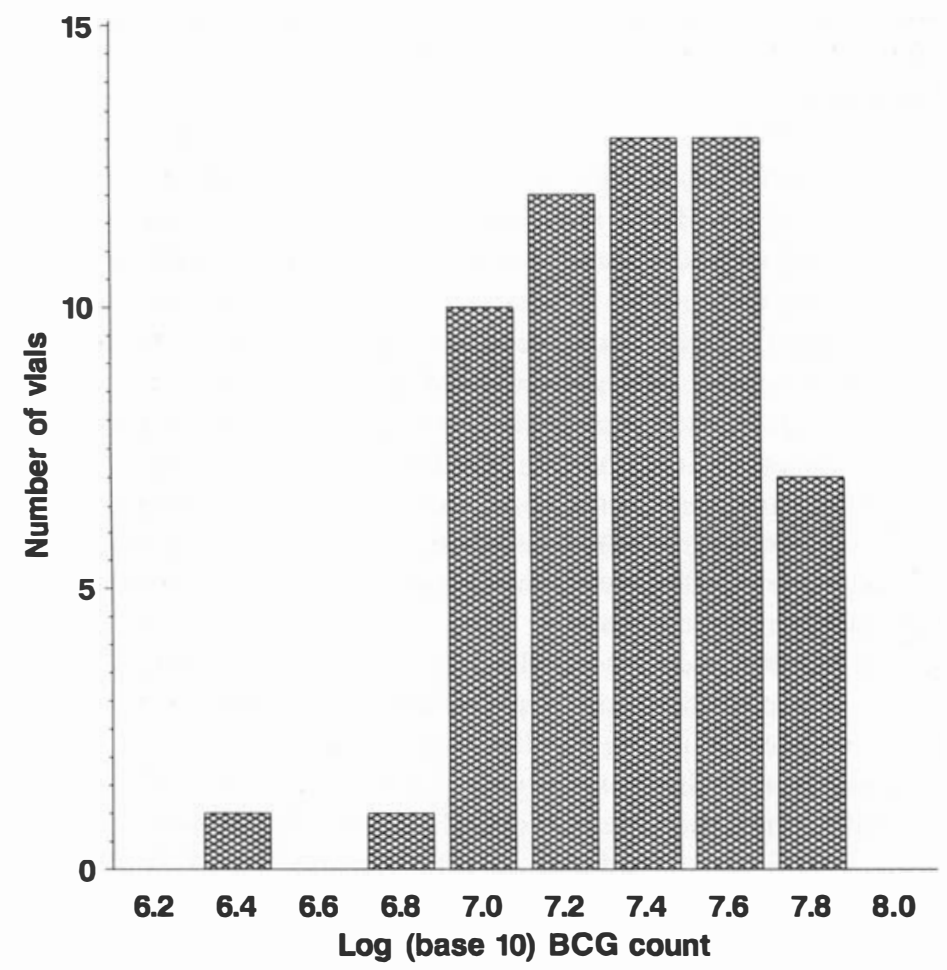

Figure 5. Counts of viable BCG in 57 vials collected from paraffin fridges in the field during the intake phase of the Karonga Prevention Trial (1986-89). Counts are per vial, thus per 10 doses. 
control were collected from the field and the field staff were not aware of the timing and the purpose of the collection. There is no reason to believe that the staff responsible for the cold chain (office staff, drivers and vaccinators) took more care than usual concerning the delivery and storage of vaccines during the weeks preceding the collection of BCG vials.

Of real concern is how of ten a wrong label was copied or stuck onto an examination form. All unused code labels were supposed to be destroyed after each vial was finished, and before reconstitution of the next vial. As only 2 vials were open at any time, mistakes should only have occurred when the vaccinator stuck a scar-positive label onto an examination form even though a scar-negative vaccine had been given, and vice-versa. The data on post-vaccination skin-test induration sizes in the placebo group (Table 5) show no evidence for such errors. On the other hand, of 248 BCG scar-positive individuals who were recorded as having received a placebo injection, and who were examined for an ulcer 4 weeks after vaccination, 8 were recorded as having an ulcer in the right deltoid area.

Are there explanations apart from the wrong labels being used in these 8 instances? None of the other individuals who had been vaccinated from the same (8) vials was observed to have developed an ulcer; thus there is no indication that the vials themselves were mislabelled. This leaves 3 alternative explanations: (i) the ulcers, in particular the 6 ulcers which measured $1-3 \mathrm{~mm}$ in diameter, were not vaccine ulcers but represent injuries or abrasions, perhaps after insect bites; (ii) individuals were wrongly identified at the time of measuring the ulcers; or (iii) staff invented the ulcer sizes instead of going, maybe a long way, to find the individuals they had been asked to examine for vaccine ulcers. The last explanation cannot be discounted even though the 8 ulcers were all recorded by different staff. Given personal experience (JMP) of mistaking an ordinary ulcer (abrasion) for a vaccine ulcer, the first explanation would seem the likeliest explanation for most of the ulcers found 4 weeks after vaccination in individuals allocated to placebo only.

A discrepancy between BCG scar status and vaccine given was found in 153 $(63+44+39+7$, see above $)$ individuals. Such errors may have arisen in several ways. For example, if a vaccinator went alone to vaccinate a child after he/she had recovered from measles, the vaccinator might have seen no obvious BCG vaccination scar and overlooked the fact that the LCA had recorded that there was a (doubtful) scar. If the label of the vaccine actually used was stuck onto the examination form, such mistakes do not matter greatly. However, it is possible that for some of these 153 individuals a wrong vaccine code label was attached to the form. Any such mistakes will lead in theory to a reduction of observed protective efficacies of the various vaccines employed in the trial.

Some individuals were undoubtedly misclassified concerning their BCG scar status, ${ }^{14}$ but their number will never be known.

Approximately 121,000 people were ultimately recruited into the Karonga Prevention Trial, which is very close to the number predicted. ${ }^{2}$ The numbers who refused and who were ineligible for vaccination were smaller than expected.

At present we expect that the first analyses of protective effects of the trial vaccines will be carried out in 1995. Until then the trial population will be followed by a combination of 'enhanced passive surveillance' (individuals are examined by LCAs for signs of leprosy whenever they have contact with health services in the district, be it as patients, guardians of patients, or as attenders of ante-natal or under-5s clinics) and sample surveys in high incidence areas and in areas far from any health service facility. Approximately $50 \%$ of the trial population had been re-examined by one or other of these methods by late 1992 . 


\section{Acknowledgements}

The Lepra Evaluation Project/Karonga Prevention Trial is funded by LEPRA (The British Leprosy Relief Association), ILEP (The International Federation of AntiLeprosy Organizations) and IMMLEP (The Immunology of Leprosy component of the WHO/TDR). The authors wish to thank the Government of the Republic of Malawi for their interest in and support of the trial and Glaxo for providing the BCG and placebo. We are indebted to chiefs Kyungu, Kilupula and Wasambo and to the District Party Chairman, Mr Bonga Gondwe, of the Malawi Congress Party, for their help. Our sincere thanks go to the people of Karongo District for their co-operation without which this trial could not have taken place.

All the KPT staff worked hard, often away from their families for many weeks, to accomplish the intake phase of the trial.

\section{References}

1 Convit J, Sampson C, Zuniga M, Smith PG, Plata J, Silva J, Molina J, Pinardi ME, Bloom BR, Salgado A. Immunoprophylatic trial with combined Mycobacterium Leprae/BCG vaccine against leprosy preliminary results. Lancet, 1992; 339: 446-50.

2 Fine PEM, Pönnighaus JM. Background, design and prospects of the Karonga Prevention Trial, a leprosy vaccine trial in Northern Malawi. Trans Roy Soc Trop Med Hvg, 1988; 82: 810-17.

3 WHO. Tropical disease progress in reassessing 1989-1990. 10th Programme report of the UNDP/World Bank/Who Special. WHO: Geneva, 1991.

${ }^{4}$ Kartikeyan S, Chaturvedi RM, Deo MG. The sociocultural dimension in leprosy vaccine trials. Lepr Rev, 1990; 61: 50-9.

${ }^{5}$ Fine PEM. BCG vaccination against tuberculosis and leprosy. Brit Med Bull 1988; 44: 691-703.

${ }^{6}$ Pönnighaus JM, Fine PEM, Bliss L, Sliney IJ, Bradley DJ, Rees RJW. The Lepra Evaluation Project (LEP), an epidemiological study of leprosy in Northern Malaŵi. I. Methods. Lepr Rev, 1987; 58: 359-75.

7 National Statistical Office. Malâîi Population and Housing Census 1987. Preliminary Report. Zomba, 1989.

8 Pönnighaus JM, Fine PEM. Sensitization studies with potential leprosy vaccine preparations in Northern Malawi. Int J Lepr, 1986; 54: 25-37.

9 WHO. Report of the Fifth Meeting of the Scientific Working Group on Immunology of Leprosy. Protocol 1/ 79. TDR/SWG/IMMLEP (5) 80.31980.

${ }^{10}$ Immunization in practice. A guide for health workers who give vaccines. EPI/PHW/84/2 Rev. 1. Geneva: WHO.

1 Smelt AHM, Rees RJW, Liew FY. Induction of delayed-type hypersensitivity to $M$. leprae in healthy individuals. Clin exp Imm, 1981; 44: 501-6.

12 Soko BJ. The vimbuza phenomenon: disease or art. Thesis (1982). University of Malawi, Chancellor College, P.O. Box 280, Zomba, Malawii.

13 Pönnighaus JM, Fine PEM, Moreno C. Hypersensitivity to dextran in BCG vaccine. Lancet, 1991; $337: 1039$ (letter).

14 Fine PEM, Ponnighaus JM, Maine N. The distribution and implications of BCG scars, with particular reference to a population in Northern Malawi. Bulletin of the World Health Organization 1989; 67 (1): 35-42. 


\title{
L'étude de prévention de Karonga: une étude de vaccin contre la lèpre et la tuberculose en Malawi du nord. I. Méthodes adoptées pour la phase de vaccination
}

\author{
J. M. Ponnighaus, P. E. M. Fine, L. Bliss, P. J. K. Gruer, \\ B. Kapira-Mwamondwe, E. Msosa, R. J. W. Rees, D. Clayton, \\ M. C. Pike, J. A. C. Sterne et S. M. Oxborrow
}

Résumé Nous décrivons en détail les méthodes adoptées pour l'étude de prévention de Karonga, une étude à double aveugle de vaccin contre la lèpre et la tuberculose dans le district de Karonga en Malawi du nord. Au cours d'une enquête porte-à-porte recouvrant la population totale, qui a commencé en novembre 1985 et s'est terminée en août 1989,121.008 personnes (57.892 personnes de sexe masculin et 63.116 de sexe féminin) ont été vaccinées. 5835 autres personnes ont ref usé de se faire vacciner et 5757 autres n'étaient pas admissibles à la vaccination, 2652 d'entre elles parce qu'elles avaient des antécédents de signes de lèpre ou parce qu'elles étaient présumées atteintes de lèpre précoce. Un total de 66.145 personnes chez lesquelles aucun signe apparent de BCG antérieur, n’a été détecté, one été vaccinées comme suit: BCG, BCG $+5 \times 10^{7}$ de Mycobacterium leprae tués, ou $\mathrm{BCG}+6 \times 10^{8}$ de $M$. leprae tués; 54.863 personnes qui présentaient une cicatrice typique ou douteuse de BCG ont été vaccinées au placebo, au BCG ou (à partir du milieu de l’année 1987) au BCG $+6 \times 10^{8}$ de M. leprae tués. Les effets secondaires n'ont pas été recherchés systématiquement mais quatre personnes signalèrent d'ellemêmes des abcès glandulaires, neuf personnes de grands ulcères post-vaccination ( $>25 \mathrm{~mm}$ de diamètre) et deux, des ulcères qui ont duré plus d'un an.

Les foiles de BCG recueillies sur le terrain dans des réfrigérateurs à pétrole, avaient des concentrations satisfaisantes de BCG viable pendant toute la durée de l'étude.

Les résultats des tests cutanés post-vaccination (RT23 et l'antigène soluble du $M$. leprae) et les taux d'ulcères post-vaccination indiquent que seules quelques erreurs ont été faites sur le terrain en notant le code des vaccins.

\section{Ensayo preventivo de Karonga: ensayo de vacuna contra la lepra y la tuberculosis en Malawi del Norte. I. Métodos de la fase de vacunación}

\author{
J. M. Pönnighaus, P. E. M. Fine, L. Bliss, J. K. Gruer, \\ B. Kapira-Mwamondwe, E. Msosa, R. J. W. Rees, D. Clayton, \\ M. C. Pike, J. A. C. Sterne y S. M. Oxborrow
}

Resumen Se describen en detalle los métodos del Ensayo de Prevensión de Karonga, un ensayo doble ciego de vacuna contra la lepra y la tuberculosis en el Distrito de Karonga, Malawi del Norte. Durante una campaña de la población total, casa por casa, que duró desde noviembre de 1985 hasta agosto de 1989, se vacunó a 121.008 personas ( 57.892 hombres y 63.116 mujeres). Otras 5.852 personas se negaron a ser vacunadas, y 5.757 no resultaron aptas para la vacunación, de las cuales, 2.652 tenían antecedentes o señales de lepra, o porque se sospechaba estaban en las etapas tempranas de la enfermedad. Un total de 66.145 individuos sin evidencia de previa vacunación $\mathrm{BCG}$ recibieron una de las siguientes vacunas: $\mathrm{BCG}, \mathrm{BCG}+5 \times 10^{7}$ Mycobacterium leprae eliminados, o $\mathrm{BCG}+6 \times 10^{8} \mathrm{M}$. leprae eliminados; 54.863 individuos que presentaron una típica o dudosa cicatriz de BCG recibieron placebo, o BCG, o (desde mediados de 1987 en adelante) $\mathrm{BCG}+6 \times 10^{8}$ M. leprae eliminados. No se buscaron ef ectos adversos en forma sistemática. pero cuatro individuos se presentaron para denunciar abscesos, nueve individuos denunciaron grandes úlceras posteriores a la vacunación $(>25 \mathrm{~mm}$ de diámetro), y dos denunciaron úlceras que perduraron más de un año. Las ampollas de BCG recogidas de los refrigeradores de parafina en campo mostraron concentraciones satisfactorias de BCG viables durante todo el ensayo. Los resultados de las pruebas cutáneas posteriores a la vacunación (RT23 y antígeno soluble de $M$. leprae) y los índices de úlceras posteriores a la vacunación indican que se ef ectuaron pocos errores en campo al registrar los códigos de las vacunas. 